\title{
A PILOT STUDY ON THE EFFICACY OF AN INDIGENOUS ANTICANCER FORMULATION (AC COMPOUND) IN
} PATIENTS OF CANCER

\author{
Prof. Radheyshyam Sharma ${ }^{1}$, Dr. Anamika Soni ${ }^{2}$
}

${ }^{1}$ Ex. Vice Chancellor, DR. SR RAU, Jodhpur, Rajasthan

${ }^{2}$ Assistant Professor, PG Dept. of Kaya Chikitsa, Incharge Cancer Research Unit, Dr SR RAU, Jodhpur, Rajasthan

Article Info: Received 10 January 2020; Accepted 27 February 2020

DOI: https://doi.org/10.32553/jbpr.v9i1.722

Corresponding author: Prof. Radheyshyam Sharma

Conflict of interest statement: No conflict of interest

\section{ABSTRACT:}

Cancer is second to coronary artery disease as being the commonest cause of death in the western world. In India, as many as 2,500 persons die every day due to tobacco-related diseases. One woman dies of cervical cancer every 8 minutes in India. In Modern medicine, the available treatment modalities viz chemotherapy and radiotherapy cause decrease in immunity, decreased Quality of life, poor tolerance to surgery and altered efficacy of Chemotherapy and Radiotherapy. Ancient Ayurveda classics have described about tumours as 'Arbuda'. Ayurveda can be helpful in the management of cancer in many ways- as prophylactic, palliative, curative or supportive therapy. No doubt, it helps to improve quality of life ( $Q O L)$ as adjuvant or as co therapy along with chemotherapy or radio therapy \& Post surgery care. Ayurvedic drugs also minimize the side effects of Chemo/radio and other therapies. So, the current pilot study was done with the motive to evaluate the effect of a hypothetical compound (AC Compound) in the patients of Cancer. A significant improvement in some of subjective parameters like general well being, pain, indigestion, constipation and headache was seen in patients as a result of therapy. The results obtained from trial encourage more exploration and extended clinical trials in this field.

Keywords: Immunity, Chemotherapy, Radiotherapy, Arbuda, AC compound

\section{INTRODUCTION}

Cancer is second to coronary artery disease as being the commonest cause of death in the western world. An estimated 7.4 million males were diagnosed with cancer worldwide in 2012. Lung cancer was the most common, accounting for almost a fifth (17\%) of all cases diagnosed as cancer. Prostate cancer being the second most common cancer diagnosed in males worldwide (15\%). Bowel, stomach and liver cancers are the remaining of the five most common cancers in males in the world, accounting for $10 \%, 9 \%$ and $7 \%$ of the male total, respectively ${ }^{1}$.An estimated 6.7 million females were diagnosed with cancer worldwide in 2012. Breast cancer being the most common, accounting for a quarter (25\%) of all cases diagnosed. Bowel cancer was as the second most common cancer diagnosed in females worldwide (9\%). Lung, cervical and stomach cancers are the remaining of the five most common cancers in females worldwide, accounting for $9 \%, 8 \%$ and $5 \%$ of the female total, respectively ${ }^{2}$. One woman dies of cervical cancer every 8 minutes in India ${ }^{3}$ As many as 2,500 persons die every day due to tobacco-related diseases in India ${ }^{4}$. In Modern medicine, the available treatment modalities viz chemotherapy and radiotherapy cause serious side effects, decrease in immunity, decreased Quality of life, poor tolerance to surgery and altered efficacy of Chemotherapy and Radiotherapy.

Ancient Ayurveda classics have described about tumours as arbuda. Doshas vitiated in any part of the body and afflicting the Mamsa dhatu produce a swelling, which is circular, fixed, slightly painful, big in size, broad based, slowly growing and does not suppurate ${ }^{5}$ Acharya Charkha has described Arbuda as a complication of Vata - Rakta. Acharya Madhava while describing the definition of Arbuda opines that the vitiated Doshas afflict the Mamsa and Rakta dhatu to produce a swelling i.e Arbuda $^{6}$.The clinical manifestation of oncological entities or cancer is similar to pathology and clinical presentation of diseases Shotha, Granthi, Arbuda, Apachi, Gulma Dushta vrana and Vidraddhi. Moreover many cancers like lukaemias are described under Pandu roga. The disease begins in the form of Shotha (swelling) and with the span of time gets converted to $\mathrm{Arbuda}^{7}$. The ayurvedic principles of management comprise of using Tridoshashamaka, , Srotoshodhaka, Shothahara, Granthihara, Lekhana, Vayasthapana, Balya and Rasayana drugs along with nidana parivarjana (dietary and lifestyle modifications). 
Ayurveda can offer support and comfort for the cancer patients. Ayurveda can be helpful in the management of cancer in many ways, as prophylactic, palliative, curative \& supportive and no doubt it helps to improve quality of life $(\mathrm{QOL})$ as adjuvant or co therapy along with chemotherapy / radio therapy or as Post surgery care to minimize the side effects of these therapies. Ayurveda helps in many ways to patients of cancer as mentioned above or to slower the progress of the cancer or when Chemo/ Radiotherapy or Surgery is contraindicated or for patients have no other choice for many reasons.

Need of Study - The problem of Cancer has been chosen for the study as many factors demand attention and research in this field. There is increase in incidence globally and therapies available till the date are not much satisfactory and have serious adverse effects. Extensive research has been done in this field not only in modern medicine. Indigenous and many other healing methods are being explored. Ayurveda can offer a very good support and comfort to the cancer patients. Ayurvedic treatment can be helpful in the management of cancer in many ways, as prophylactic, palliative, curative \& supportive and no doubt may help to improve quality of life (QOL). The Ayurvedic therapeutic principles and drugs can be used as primary or adjuvant or co therapy along with chemotherapy or radio therapy or Post surgery care to minimize the side effects of other therapies.

\section{Aims \& Objectives:}

- To design the Aetiopathogenesis of Cancer in Ayurvedic perspective.

- To study the efficacy of Trial drug 'AC compound' in cancer patients.

- To study the efficacy of trial drug in reducing the toxic effects of radiotherapy and chemotherapy in patients of Cancer.

- To study the efficacy of AC compound in improving the overall quality of life in patients of cancer.

- To provide an safe and cost effective therapy to the patients of Cancer

\section{Material \& Methods:}

Source and Selection of cases: 20 well diagnosed and confirmed Patients of cancer visiting Cancer research unit \& Opd of University college of Ayurveda attached Hospital, Jodhpur were selected and registered randomly for trial. Patients were subjected to the detailed clinical history and physical examination on the basis of specially prepared research Performa.

Patients consent will be taken in prescribed Performa before trial.

Study design: Open randomized trial. Inclusion criteria:
- All well diagnosed \& histopathologically confirmed cases of cancer.

- Patient with all stages of cancer

- Patients with both Primary, Secondary (metastatic) stages

- Patients of Age group 16-70 years.

- Patients of both sexes

- Patients of cancer on radiotherapy or chemotherapy

- Patients of cancer in which surgery/ chemo or radiotherapy was not recommended or indicated.

Exclusion criteria:

Cancer patients with any other serious, Acute or toxic condition were excluded from study.

Discontinuation Criteria: Following patients were discontinued from trial -

- Patients not willing to continue the treatment.

- If any severe adverse effects appear during the treatment.

- If some other serious illness occurs during trial which require any emergency intervention.

Table 1: Trial Drug: The trial drug was a polyherbal formulation with following ingredients -

\begin{tabular}{|l|l|l|l|l|}
\hline S.N & Name of Drug & Botanical name & Part Used & $\begin{array}{l}\text { Quantity } \\
\text { (in Parts) }\end{array}$ \\
\hline 1 & Madhuyashti & Glycerrhiza glabra & Root & 1 \\
\hline 2 & Giloya & Tinospora cordifolia & Root & 1 \\
\hline 3 & Bala & Sida cordifolia & Root & 1 \\
\hline 4 & Ashwagandha & Curcuma longa & Root & 1 \\
\hline 5 & Rasna & Pluchea lanceolata & Leaves & 1 \\
\hline 6 & Haritaki & Terminalia chebula & Fruit & 1 \\
\hline 7 & Amalaki & Embelica officinalis & Fruit & 1 \\
\hline 8 & Haridra & Curcuma longa & Rhizome & 1 \\
\hline 9 & Daruharidra & Barberis aristata & Rhizome & 1 \\
\hline 10 & Shalparni & Desmodium & Leaves & 1 \\
& & gangeticum & & \\
\hline 11 & Shigru & Moringa oliefera & Bark & 1 \\
\hline 12 & Manjishtha & Rubia cordifolia & Root & 1 \\
\hline 13 & Punarnava & Boerhavia diffusa & Root & 1 \\
\hline 14 & Tulsi & Osimum sanctum & Leaves & 1 \\
\hline 15 & Kutki & Pcrorrhiza curroa & Root & $1 / 2$ \\
\hline 16 & Kanchnara & Bauhinia variegata & Bark & 1 \\
\hline 17 & Sadabahar & Lochnera rosea & Leaves & 1 \\
\hline 18 & Gugglu & Commiphora mukul & Resin & Q.S \\
\hline 19 & Gomutra & Cow Urine & Urine & Q.S \\
\hline
\end{tabular}

Method of preparation of trial drug: The decoction of ingredients from $1-17$ was prepared by classical method by boiling in four time water and reducing to one fourth part of total quantity. Then obtained decoction was then boiled on medium flame till semisolid form Ghana is obtained which was then mixed with Gomutrabhawita Gugglu. Pills (Ghanavati) were prepared and air dried.

\section{Dosage and Duration of trial:}

Trial drug was given in dose of $500 \mathrm{mg}$ ( 2 tablets of 250 $\mathrm{mg}$ each), three times a day ( $1.5 \mathrm{gm} /$ day) with Gomutra Arka (distilled Cow urine) as Anupana for 2 months.

Follow up - At every 15 days during the trial and 1 month after completion of trial. 
Criteria of assessment: All the patients registered for the present clinical trial were screened for their demographic profile like age, sex, religion, marital status, socioeconomic status, occupation, addiction, Prakriti, Ahara etc. During the trial and follow-up study the patients were assessed on the basis of subjective and objective parameters. All patients registered for the trial were specifically asked for any changes in their clinical manifestations. The clinical features were rated on rating scale designed for the current trial from 0 to 4 .

\section{Observations:}

A total of 20 patients were registered from the O.P.D. and I.P.D., Department of Kayachikitsha, Dr. SR RAU ,Jodhpur, Rajasthan. 6 Patients did not return for further follow up treatment. One registered patient died during coure of treatment. The study was completed in 13 cases. Among selected patients , $5 \%$ patients belonged to the age group $16-30 \mathrm{yrs}, 15 \%$ belonged to the age group 31 - 40 yrs, 35\% belonged to the age group $41-50$ yrs, $15 \%$ belonged to the age group 51 - 60 yrs and $20 \%$ belonged to the age group 61-70 yrs of age. Among registered patient $55 \%$ patients were male and $45 \%$ patients were female. $25 \%$ patients had head and cancer, $5 \%$ patients were of lung cancer, $25 \%$ patients were having liver and gall bladder cancer, 5\% patients had Uterus/cervix/ovary cancer and $5 \%$ patients had breast cancer.20\% patients had history of HTN and $5 \%$ were having past history of DM+HTN both.5\% patients were from lower middle, $85 \%$ were from middle and 10 $\%$, belonged to upper middle class .Among registered patients, $10 \%$ patients had addiction of smoking, $10 \%$ patients had h/o addiction to gutkha (tobacco), $5 \%$ were addicted to alcohol whereas $50 \%$ patients were having addiction of tea only. Among the registered patients, 15\% patients were of Vata Pitta dominant Prakriti, 20\% of them had Pitta kapha, whereas 65\% were of Vata Kapha prakrati. 100\% patients had Rajasika mindsetup. $55 \%$ patients were of Madhyam Satva, , where as $45 \%$ had Avara Satwa. $30 \%$ patients had Madhyam jaran shakti whereas $70 \%$ were avara jaran shakti. The effect on various subjective and objective parameters have been shown in tables below-

Table 1: Effect of therapy on subjective parameters

\begin{tabular}{|c|c|c|c|c|c|c|c|c|c|}
\hline Subjective Parameter & $\mathbf{n}$ & Mean & & & $\%$ relief & S.D & S.E & "p" & Results \\
\hline & & BT & AT & $\mathrm{x}$ & & & & & \\
\hline General well being & 13 & 1.813 & 0.8750 & 0.9375 & $51.71 \%$ & 0.6801 & 0.170 & 0.001 & VS \\
\hline Pain & 9 & 1.500 & 0.8750 & 0.6250 & $41.67 \%$ & 0.8062 & 0.2016 & 0.017 & $\mathrm{~S}$ \\
\hline Loss of appetite & 8 & 1.000 & 0.3125 & 0.6875 & $68.75 \%$ & 0.7932 & 0.1980 & 0.001 & VS \\
\hline Indigestion & 8 & 0.7500 & 0.3750 & 0.3750 & $50 \%$ & 0.6191 & 0.1548 & 0.054 & NS \\
\hline Constipation & 3 & 0.3750 & 0.0625 & 0.3125 & $83.33 \%$ & 0.6021 & 0.1505 & 0.125 & NS \\
\hline Nausea\& Vomiting & 1 & 0.2500 & 0.1875 & 0.0625 & $25 \%$ & 0.2500 & 0.0625 & 0.999 & NS \\
\hline Diarrhoea & 2 & 0.4375 & 0.4375 & 0.000 & $0 \%$ & 0.3651 & 0.0912 & 0.999 & NS \\
\hline Dysphagia & 2 & 0.4375 & 0.4375 & 0.000 & $0 \%$ & 0.3651 & 0.0912 & 0.999 & NS \\
\hline Dyspnoea & 4 & 0.5625 & 0.375 & 0.1875 & $10.54 \%$ & 0.5439 & 0.1361 & 0.3125 & NS \\
\hline Cough & 2 & 0.4375 & 0.4375 & 0.000 & $0 \%$ & 0.3650 & 0.0912 & 0.999 & NS \\
\hline Heamorrgic tendencies & 1 & 0.7500 & 0.125 & 0.625 & $83.33 \%$ & 0.8062 & 0.2016 & 0.0156 & $S$ \\
\hline Leg cramps & 7 & 0.7500 & 0.1235 & 0.4375 & $58.33 \%$ & 0.5123 & 0.1281 & 0.00156 & $\mathrm{~S}$ \\
\hline Burning sensation & 4 & 0.5000 & 0.2500 & 0.2500 & $50 \%$ & 0.4472 & 0.1118 & 0.1025 & NS \\
\hline Vertigo & 2 & 0.1875 & 0.0625 & 0.1250 & $66.67 \%$ & 0.3416 & 0.08539 & 0.5000 & NS \\
\hline Insomnia & 3 & 0.4375 & 0.2500 & 0.1875 & $42.86 \%$ & 0.4031 & 0.10080 & 0.2500 & NS \\
\hline Headache & 7 & 0.6250 & 0.1875 & 0.4375 & ; & 0.5123 & 0.1281 & 0.0156 & $S$ \\
\hline Pruritus & 4 & 0.4375 & 0.1875 & 0.2500 & $57.14 \%$ & 0.8563 & 0.2141 & 0.3750 & NS \\
\hline Excessive thirst & 6 & 0.5625 & 0.1250 & 0.4375 & $77.78 \%$ & 0.6292 & 0.1573 & 0.0313 & $\mathrm{~S}$ \\
\hline Weight loss & 3 & 0.1250 & 0.4375 & 0.3125 & $\%$ & 0.6021 & 0.1505 & 0.1250 & NS \\
\hline Lymphadenopathy & 1 & 0.6250 & 0.6875 & 0.0625 & $10 \%$ & 0.2500 & 0.06250 & 0.9999 & NS \\
\hline Hair loss & 1 & 0.1250 & 0.0625 & 0.0625 & $50 \%$ & 0.2500 & 0.06250 & 0.999 & NS \\
\hline
\end{tabular}


Table 2: Effect if therapy on Objective parameters

\begin{tabular}{|c|c|c|c|c|c|c|c|c|c|c|}
\hline Biochemical Profile & $\bar{n}$ & Mean & & & \% change & SD & SE & $\mathrm{t}$ & $p$ & Results \\
\hline & & BT & AT & $\mathrm{x}$ & & & & & & \\
\hline Hbgm\% & 5 & 10.740 & 10.940 & 0.2000 & $-0.0186 \%$ & 1.681 & 0.7517 & 0.2661 & 0.8033 & NS \\
\hline TLC & 5 & 66868 & 70564 & 3696 & $-0.0552 \%$ & 17500 & 7826.1 & 0.4723 & 0.6613 & NS \\
\hline PLT & 5 & 105300 & 190280 & 84980 & $-0.8070 \%$ & 103253 & 46176 & 1.8404 & 0.1390 & NS \\
\hline Blood Urea & 2 & 23.55 & 21.03 & 2.515 & $0.10699 \%$ & 0.181 & 5.785 & 0.4347 & 0.7389 & NS \\
\hline Serum creatinine & 2 & 0.9600 & 0.7900 & 0.1700 & $0.1770 \%$ & 0.3250 & 0.2300 & 0.7391 & 0.5948 & NS \\
\hline Alkalinephosphatase & 5 & 393.06 & 275.58 & 117.48 & $0.2988 \%$ & 314.25 & 140.54 & 0.8359 & 0.4502 & NS \\
\hline SerumBilirubin total & 4 & 5.045 & 6.853 & 1.808 & $-0.3583 \%$ & 3.665 & 1.832 & 0.9864 & 0.3967 & NS \\
\hline SGOT & 5 & 136.57 & 47.744 & 88.956 & $0.6507 \%$ & 148.91 & 66.595 & 1.336 & 0.2526 & NS \\
\hline SGPT & 5 & 133.80 & 43.492 & 90.310 & $0.6749 \%$ & 138.3 & 61.850 & 1.460 & 0.218 & NS \\
\hline Serum cholesterol & 2 & 165.60 & 163.55 & 2.050 & $0.01237 \%$ & 22.69 & 16.050 & 0.1277 & 0.9191 & NS \\
\hline Serum triglycerides & 2 & 159.35 & 159.00 & 0.3500 & $0.0021 \%$ & 19.304 & 13.650 & 0.0256 & 0.9837 & NS \\
\hline RBS & 2 & 101.20 & 96.550 & 4.650 & $0.0459 \%$ & 0.91920 & 0.6500 & 7.7540 & 0.0884 & NS \\
\hline
\end{tabular}

\section{Discussion:}

The incidence and mortality of Cancer is increasing very rapidly. No satisfactory therapy has been found so far though vast research is ongoing in this field. The current research study was designed with the aim of providing some contribution to medical science for the wellfare of society specifically to the patients of Cancer. As per ayurveda principles, Doshas afflict the Mamsa and Rakta dhatu to produce a swelling i.e Arbuda. The clinical manifestation of oncological entities or cancer is similar to pathology and clinical presentation of diseases described in Ayurveda under nomenclature of Shotha, Granthi, Arbuda, Apachi, Gulma Dushta vrana and Vidradhi. Cancers like lukaemias are described under Panduroga. The disease usually begins in the form of Shotha (swelling) and may get converted into Arbuda (tumour).

In current trial, most patients were male with age group 31- 45 years with history of addiction to tobacco/gutakha and Tea. Most patients were of liver\& gall bladder cancer and cancer of Head and neck. Most patients had Vata pitta dominant and rajasika Prakriti showing role of Prakriti in pathogenesis of cancer. The trial drug showed stastically significant improvement in symptoms of feeling of general wellbeing, loss of appetite, pain, hemorrhagic tendencies, leg cramps, excessive thirst and headache. Though the Ac compound also showed significant improvement in LFT profile in 2 registered patients and also decrease in cancer markers in one patient but statstically the results were insignificant. The trial drug used on the therapeutic principles with multiple systemic actions on Srotas, Agni, dosha, dhatus and Oja in body viz. Tridoshashamaka, Raktashodhaka, Srotoshodhaka, Agnideepana, Rasayana, Vayasthapan, antioxidant, antitumour and antimetastatic actions of the ingredients used in formulation of trial drug. Drugs like
Aswagandha, Bala, Madhuyashti \& Punarnava are having immunomodulator, dhatubalaya and rasayan properties. Drugs like Haritaki, Amalaki and Shigru has Amapachaka (alleviates toxins) and antiinflammatory effects. Drugs like Giloya, Tulsi have Agnideepana, antioxidant and immunebooster actions. Haridra, daruharidra ,Katuki and manjishtha have antiinflammatory, antioxidant and raktashodhaka effects. Kanchnara and Sadabahaar have anticancerous properties. Gugglu has antiinflammatory, Shothhara and Tridoshahara effects. Cow urine has been found to possess anticancerous effects in various studies. Though, this is a small pilot study to see primary results of trial drug but it can be extended with modifications in drug, dosage and specifically with more sample size.

\section{Conclusions:}

From the current pilot study following conclusions have been withdrawn-

1. Cancer is really a dreadful condition leads to decrease in span and quality of life of patients

2. In ayurveda, the condition can be understood as severe doshik imbalance, deranged Agni, Dhatupaka and Dhatukshya for which drugs with Srotoshodhaka, Vatakaphashamka, Agnideepana, Balya, Rasayana properties must be used.

3. Trial drug showed good results in various subjective parameters though no much changes in laboratory parameters.

4. The trial drug was free from any adverse effect rather there was reduction in many toxic symptoms in patients taking allopathic treatment so we can conclude that the trial drug is also effective as co therapy and improves quality of life of cancer patients.

- For more authentic results and conclusions, the study should be extended /conducted on specific group of cancers with large sample size.

72 | P a g e 


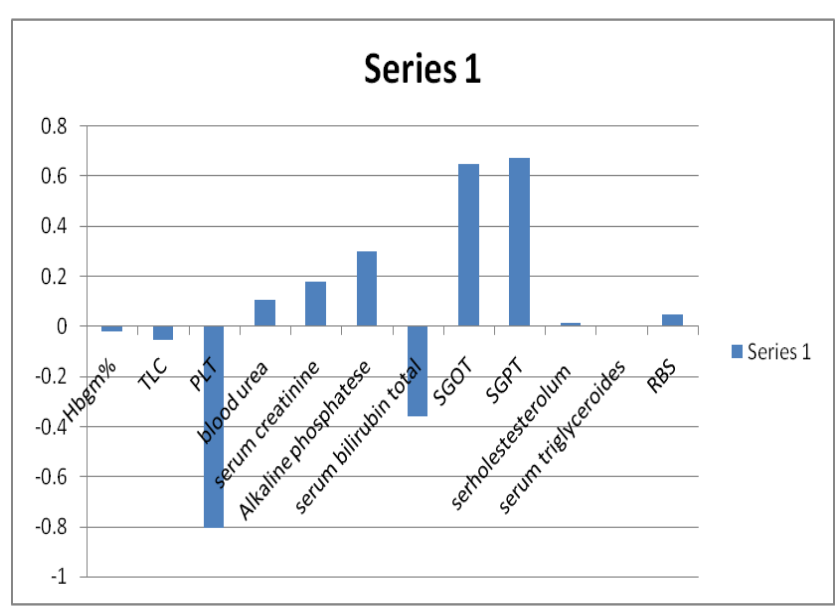

Graph showing Effect if therapy on objective parameters

\section{References:}

1. WHO, Global health observatory data repository, 2011. http:/apps.who.int/gho/data/node.main.2
2. Report on causes of deaths in India20012003.office of registrar general of India,Govt. of India,2010.

3. Nandakumar A,National cancer registry programme, ICMR, consolidated report of the population based cancerregisteries1990-96,n. Delhi 2009

4. Reddy KS,Gupta PC, Report on tobacco control in India, Ministry of health \& family welfare, N.Delhi,

5. Thakral kewal krishan,Sushruta samhita, Nidana sthana, 11/13-14, p-828, Chaukhamba orientalia publication, 2014

6. Shastri kashinath, Vidyyotini commentary, Charak samhita, Uttarardha, Chikitsa sthana, 29/34, P. N824, Chaukhambha bharti Academy, 2018.

7. Shastri sudarshan, Madhukosha Commentary, Madhava nidana 11/ 18-22, p. n. 88-90, Chaukhamba Prakashan, 2014. 